\title{
Tuning of the rotational transform in Wendelstein $7-\mathrm{X} \ddagger$
}

\author{
Samuel A. Lazerson ${ }^{1}$, Yu Gao ${ }^{2}$, Kenneth Hammond ${ }^{3}$, Carsten \\ Killer $^{3}$, Georg Schlisio ${ }^{3}$, Matthias Otte ${ }^{3}$, Christoph \\ Biedermann $^{3}$, Monica Spolaore ${ }^{4}$, Sergey Bozhenkov ${ }^{3}$, Joachim \\ Geiger $^{3}$, Olaf Grulke ${ }^{3}$, Dirk Nicolai ${ }^{2}$, Guruparan \\ Satheeswaran $^{2}$, Holger Niemann ${ }^{3}$, Marcin Jakubowski ${ }^{3}$, Peter \\ Drewelow $^{3}$, Aleix Puig Sitjes ${ }^{3}$, Adnan Ali ${ }^{3}$, Barbara Cannas ${ }^{6}$, \\ Fabio Pisano ${ }^{6}$, Ralph König ${ }^{3}$, Glen Wurden ${ }^{7}$, Gabor Kocsis ${ }^{5}$, \\ Tamás Szepesi ${ }^{5}$, Uwe Wenzel ${ }^{3}$, Matthias Mulsow ${ }^{3}$, Kian \\ Rahbarnia $^{3}$, Jonathan Schilling ${ }^{3}$, Ulrich Neuner ${ }^{3}$, Tamara \\ Andreeva $^{3}$, Henning Thomsen ${ }^{3}$ Jens Knauer ${ }^{3}$, Kai Jakob \\ Brunner $^{3}$, Boyd Blackwell ${ }^{8}$, Michael Endler ${ }^{3}$, Soren Klose ${ }^{3}$, \\ Lukas Rudischhauser ${ }^{3}$, and the W7-X Team ${ }^{3}$ \\ ${ }^{1}$ Princeton Plasma Physics Laboratory, Princeton NJ, 08543, USA \\ ${ }^{2}$ Forschungszentrum Jülich GmbH, 52425, Jülich, Germany \\ ${ }^{3}$ Max-Planck-Institut für Plasmaphysik, 17491, Greifswald, Germany \\ ${ }^{4}$ Consorzio RFX, Padua, Italy \\ ${ }^{5}$ Wigner Research Center for Physics, Budapest, Hungary \\ ${ }^{6}$ University of Cagliari, Cagliari, Italy \\ ${ }^{7}$ Los Alamos National Laboratory, Los Alamos, NM 87545, USA \\ ${ }^{8}$ Plasma Research Laboratory, Research School of Physical Sciences and Engineering, \\ The Australian National University, Canberra, Australia
}

E-mail: lazerson@pppl.gov

\begin{abstract}
The control of rotational transform in Wendelstein 7-X (W7-X) is key to both the island divertor operation and safety of plasma facing components. The island divertor concept in W7-X relies on an edge flux surface with rotational transform of $t=1$ resonating with an intrinsic $n / m=5 / 5$ resonance to form a five lobed island chain. This island chain intersects with divertor plates to give rise to the island divertor. Changes in the relative position of the rational surface and the divertor plates can result in changes in divertor performance, thus the control of the rotational transform is essential to operation of the W7-X device. During the first divertor campaign electromagnetic loads resulted in elastic deformations of the shaped modular stellarator coils. Such deformations made these coils more planar, reducing the vacuum rotational transform, subsequently shifting the $t=1$ resonance outward. Unintended

$\ddagger$ Notice: This manuscript has been authored by Princeton University under Contract Number DE-AC02-09CH11466 with the U.S. Department of Energy. The publisher, by accepting the article for publication acknowledges, that the United States Government retains a non-exclusive, paid-up, irrevocable, world-wide license to publish or reproduce the published form of this manuscript, or allow
\end{abstract} others to do so, for United States Government purposes. 
plasma wall interactions provided the first clear evidence of this effect during plasma operation. Flux surface measurements were utilized to estimate the correct level of current in the planar coils for correction of $t$, and found to be around $\sim-100 A$. Scans of the planar coil current for iota correction were performed during plasma operation. These measurements suggest planar coil currents between -250 and $\sim 0 A$ would place the strike lines at the designed distance from the pumping gaps. Divertor Langmuir and upstream probe measurements confirm these estimates along with measurements of divertor neutral gas pressure.

Submitted to: Nuclear Fusion 


\section{Introduction}

The control of rotational transform $(t)$ in Wendelstein 7-X (W7-X) has long been identified as a key aspect to the operation of the device. It has been theorized that as plasma beta increases, an increase in the bootstrap current due to neoclassical effects will result in a change of rotational transform [1]. This would in turn cause a change in the behavior of the island divertor of W7-X, possibly limiting the performance of the device or overloading certain plasma facing components. The scaling of the bootstrap current in W7-X has recently been confirmed, lending strong credibility to the idea that bootstrap currents will in fact evolve to the expected levels during high performance operation [2]. Recent measurements confirm the motion of the strike lines as the total plasma current evolves [3]. Various compensation and device protection concepts are being tested in W7-X including protective divertor elements [4], electron cyclotron current drive [5], and magnetic configuration changes. This paper discusses the latter of these methods, detailing experiments performed on W7-X using the superconducting coils to modify the edge rotational transform, comparing experiments to modeling, and making predictions for future operation.

The island divertor of W7-X is key to the experimental goals of achieving longpulse, high beta, steady-state operation, by providing a means for controlled heat and particle exhaust. The island divertor arises from an $t=1$ surface which resonates with an intrinsic $n / m=5 / 5$ field perturbation. Alternatively, $n / m=5 / 6$ and $n / m=5 / 4$ configurations are possible but we restrict this discussion to the $n / m=5 / 5$ configuration as the divertor shape and pumping have been optimized to this configuration. Figure 1 depicts the first wall and divertor structures of W7-X. Superimposed on this image are strike lines and a Poincaré plot of the standard magnetic configuration in vacuum (as calculated using the FIELDLINES code [6]). Here the five lobes of the divertor are clearly visible, forming five independent flux bundles. The divertor plates intersect these flux bundles, essentially capping both ends. The strike lines formed by this intersection are visualized in blue. Between the divertor plates is a gap which serves to allow neutral particle exhaust and pumping. In future upgrades, cryo-pumps will be located in this region.

The magnetic configuration of W7-X arises from seven unique superconducting magnetic coil shapes, mirrored across five symmetry planes, for 70 superconducting coils in total. Of the seven unique modular coil shapes, five are three-dimensionally shaped 'stellarator' coils (with 108 turns each) giving rise to the vacuum poloidal and toroidal fluxes. The other two coils are planar coils (with 36 turns each) which are located radially outside the other coils, and are tilted with respect to the the toroidal direction (see figures 1 and 2 in reference [7]). This tilting provides a flexibility in magnetic configurations. When energized with currents in phase, the planar coils provide a toroidal component to the magnetic field. This allows changes to the rotational transform through addition of toroidal flux $(t=d \chi / d \Psi$ where $\chi$ is poloidal flux and $\Psi$ is toroidal flux). Out of phase currents yield a vertical field, allowing for 


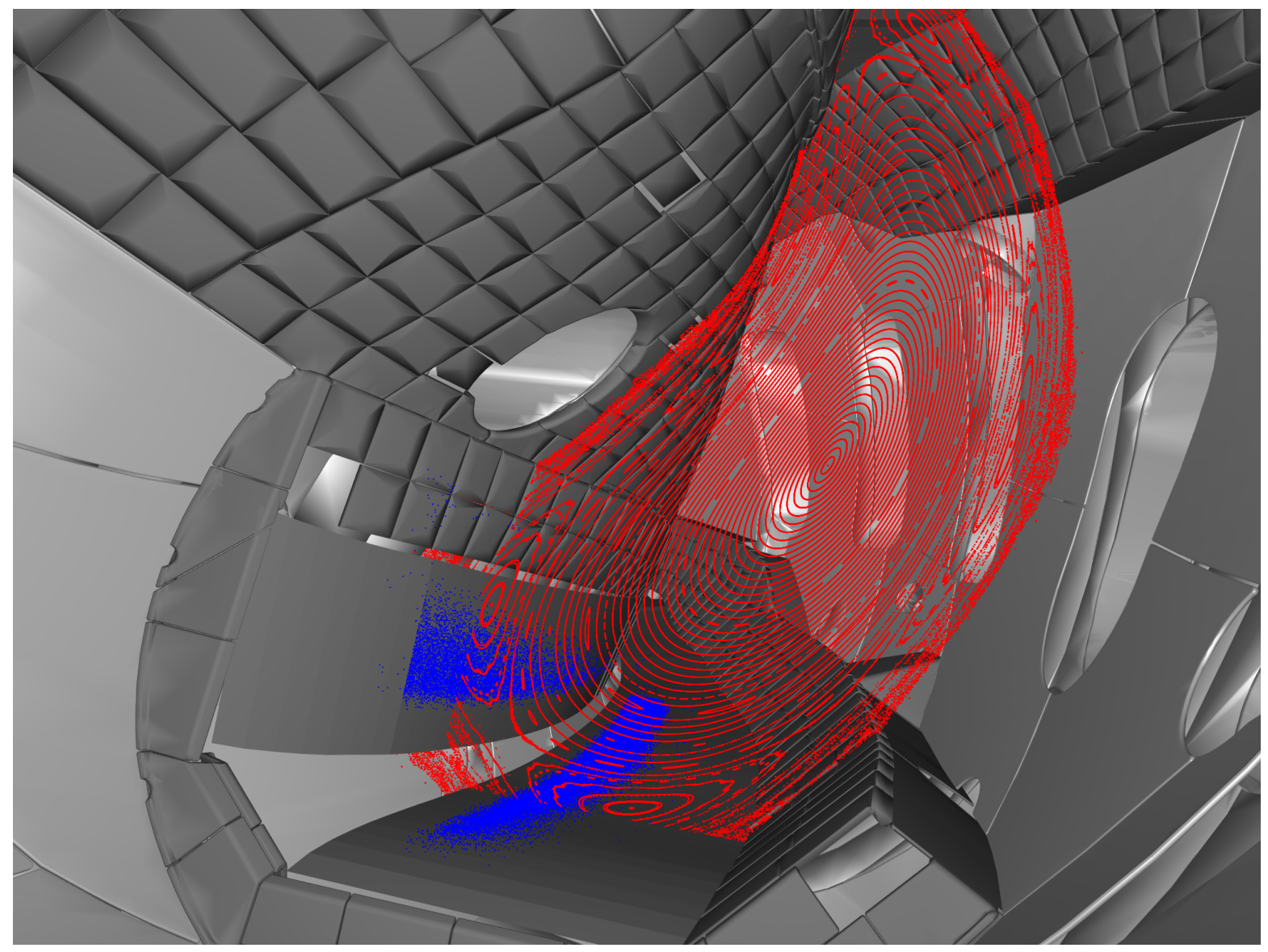

Figure 1. The W7-X divertor system with superimposed Poincaré plot (red) and field line diffusion calculation (blue) for the standard vacuum magnetic configuration using ideal coils.

changes in the radial position of the flux surfaces (albeit with additional changes to the toroidal ripple). The standard magnetic configuration is nominally achieved using zero planar coil currents and equal currents flowing in the five non-planar coil currents. Variations of the non-planar coil currents allow for changes in the predicted level of neoclassical transport (both increasing or decreasing the levels relative to the standard configuration). Such changes do not appreciably affect rotational transform but can slightly influence the shear in the edge transform profile, thereby affecting island widths (shifting the strike lines).

Features which can alter the magnetic configuration of W7-X away from its designed island divertor design have received much attention in recent years. It was identified early on that even small magnetic fields which resonate with the $t=1$ surface can modify the edge island topology, resulting in divertor overload [8]. To this end a great deal of effort was spent measuring and correcting the positioning of the superconducting coils of W7-X $[9,10]$. Early in the initial limiter experimental campaign efforts to gauge the effect of these measurements confirmed that the magnetic field was in fact accurately generated to better than one part in $100,000[11,12,13,6]$. The remnant $n / m=1 / 1$ 


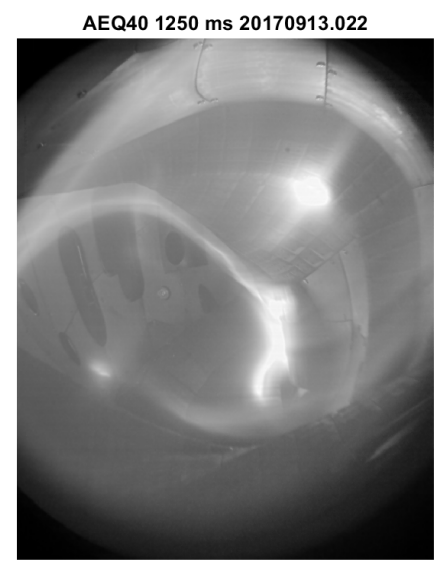

$0 \mathrm{~A}$

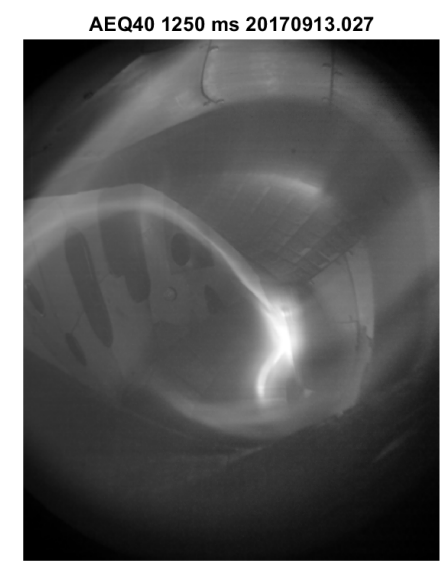

$-500 \mathrm{~A}$

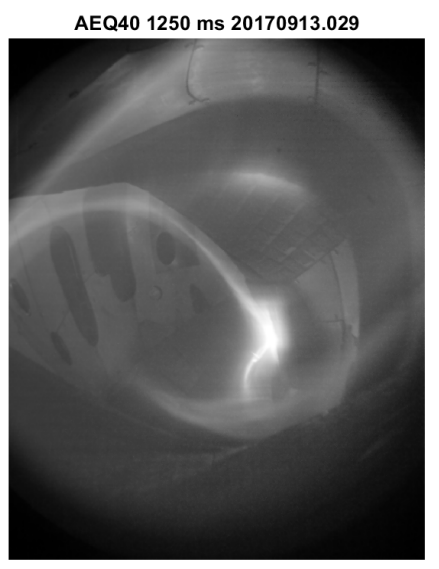

$-1000 \mathrm{~A}$

Figure 2. Video camera images (port AEQ40) showing an interaction between the carbon tiled wall and the plasma. Lower label indicates planar coil current, larger negative values indicated and increase in rotational transform. The interaction is significantly reduced and rotates poloidally as iota is increased.

field was also demonstrated to be correctible using less than $10 \%$ of the rated maximum current capacity of the trim coils $[7,14,15]$. However, during divertor operation an anomalous interaction between the plasma and carbon tiled wall elements suggested that the edge island chain was not optimally located. This was subsequently attributed to electromagnetic deformations of the non-planar superconducting coils, and efforts to measure and correct this effect were conducted. The effect of electromagnetic forces on the superconducting coils was first measured during flux surface measurements of the limiter configuration [16]. The $n / m=5 / 6$ island chain appeared to move radially outward as the field strength was increased.

Early in the first divertor campaign, during plasma operation and performance extension, visible light cameras detected an interaction between a protruding carbon wall protection element (known as the 'Abschirmhaus') and the plasma. Two such elements are located in the W7-X vessel, one to protect a diamagnetic loop, the other a soft X-ray camera array. Initially only light emission from the scrape-off layer plasma was present with no discernible load going to the wall. However, as plasma pulse length and injected energy were increased the visible light cameras detected a hot-spot on the 'Abschirmhaus' indicating significant heating of the tiles (figure 2). A series of discharges were then performed at varying levels of negative planar coil current in an attempt to minimize the interaction and allow continuation of plasma operation. This shifted the island chain radially inward and resulted in a decrease in the interaction between the plasma and the protruding wall element. The images also indicate a motion of the strike line away from the pumping gap. At that time a correction level of around $-750 A$ (symmetric in phase for all planar coils) was applied in configurations which utilized the $n / m=5 / 5$ island chain.

This paper explores the use of the superconducting planar coils to both estimate the 
change in rotational transform and correct for divertor strike line position. All results presented are for the nominal $2.52 \mathrm{~T}$ on axis magnetic field case. In the next section, we provide a theoretical estimate of how configurations changes affect the island divertor. We then review experimental measurements performed on W7-X in section 3. Finally we conclude with a discussion of the implications for future operation and reactor design in section 4.

\section{Theory and Simulations}

The proper operation of the island divertor in $\mathrm{W} 7-\mathrm{X}$ requires control of the interaction between the plasma and divertor elements. As the divertor plates themselves are fixed in space relative to the machine coordinates, active control of the magnetic fields is the most clear way to control the divertor performance. This implies that phenomena which change the magnetic field away from the optimal magnetic configuration may spoil divertor performance. Such changes can also endanger first wall elements as was documented in the previous section. However, the effects of such changes may be counteracted through various changes to the magnetic field using a variety of actuators. In this work, we specifically concern ourselves with active control of the vacuum magnetic field through use of the planar superconducting coils on W7-X. Changes to the magnetic field configuration are used to compensate reductions in the rotational transform caused by electromagnetic forces elastically deforming the non-planar superconducting coils.

The deformation of the non-planar coils and resulting reduction in rotational transform can be explained in simple terms. The self-force generated by a shaped coil due to electromagnetic loads causes the coil to deform in such a way as to become more planar. Thus in the extremal limit the coil becomes a toroidal field coil, generating only toroidal field. It can then be said that the purpose of shaping a modular stellarator coil is to generate poloidal flux (to zeroth order). Forces which reduce the level of shaping, reduce the poloidal flux and may even increase the toroidal flux (although this last effect is dependent on the initial shape of the coil). The net effect is to reduce the rotational transform of the device in vacuum. These deformations can be counteracted by a mechanical support structure, W7-X utilizes a central support ring and sliding outboard support structures for this purpose. This allows some level of deformation of the coils to occur under load while preventing damage to the coil and coil support structures.

In W7-X, the reduction of $t$ results in a radially outward motion of the edge island structure. The amplitude of this motion is a function of local shear in the rotational transform, where lower shear regions experience a larger radial shift in island position for a fixed change of $t$. The first confirmation of the presence of this effect was seen during early flux surface measurements. A scan of field strength in the limiter configuration indicated a motion of the $n / m=5 / 6$ island chain that scaled with magnetic field strength [16]. Increases in field strength (and subsequently electromagnetic load) resulted in a radially outward motion of the magnetic island chain. The effect was 


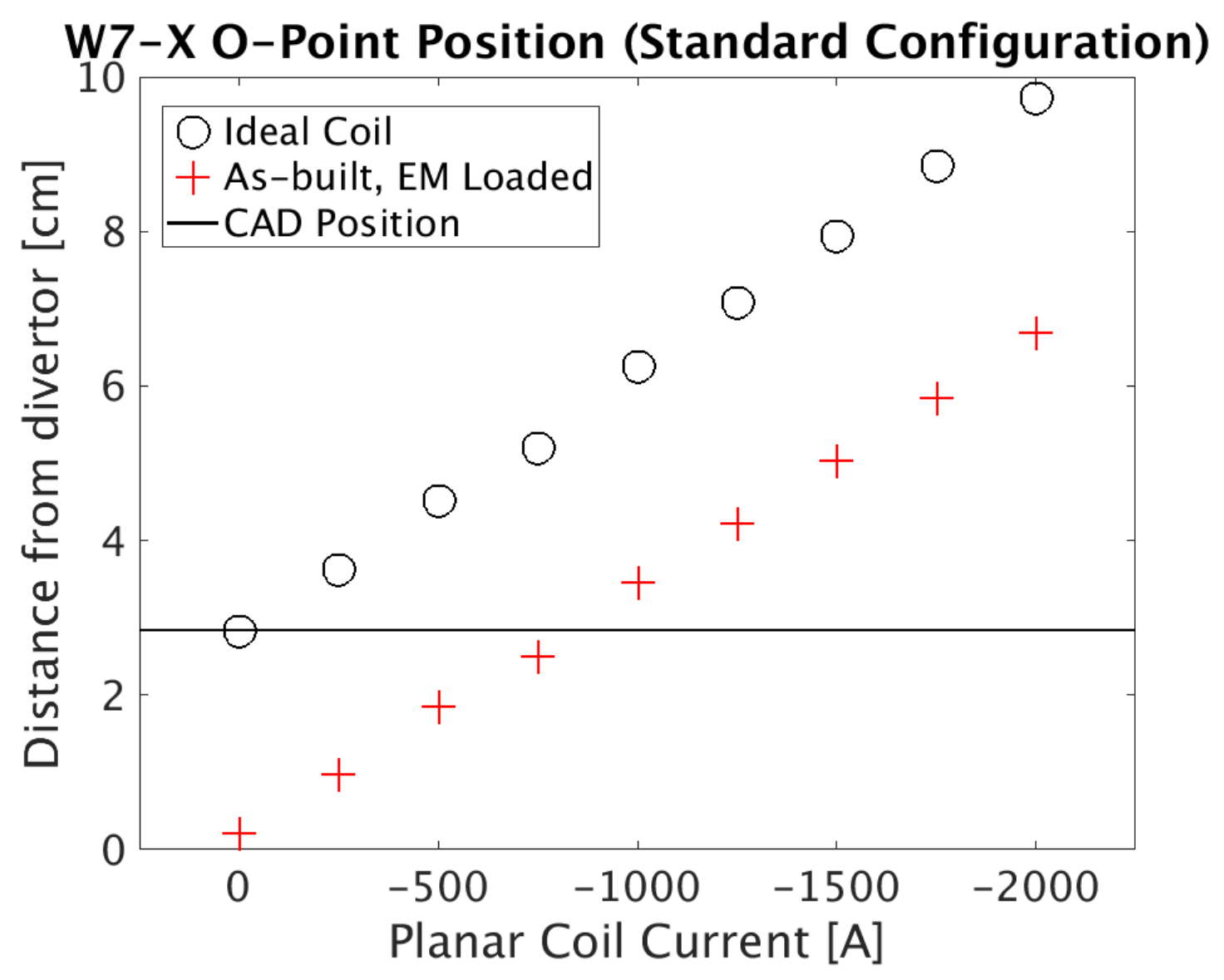

Figure 3. The position of the $\mathrm{W} 7-\mathrm{X}$ island O-points relative to the horizontal divertor for ideal coil and electromagnetically loaded as-built coil models. All data taken in the same symmetry plane $\left(\phi=-12.8^{\circ}\right)$. This location approximates the divertor finger position used later in this work. The solid line indicates the location of the O-point for the ideal CAD model.

considered to be a small deviation from the nominal configuration at full field strength (an approximately $1.5 \%$ reduction in $t$ ), and was not considered detrimental to operation with a limiter in the first experimental campaign.

In order to model such phenomena (and modes of compensation) detailed models of the magnetic coils are necessary. Such models were provided through a metrology campaign on W7-X [9]. These 'as-built' coil models are then deformed using electromagnetic (EM) simulation tools (ANSYS) [17]. In this model a $2.5 T$ field was assumed, and the coils slightly stiffened for improved fit to measurements (displacement and strain gauges [18]). The resulting 'as-built, EM loaded' coil models can then be fed into a multitude of stellarator simulations tools. Calculations of the rotational transform from field line tracing indicate a clear reduction of transform by $\Delta t \sim-0.02$ across the whole of the volume of the plasma when electromagnetic forces are taken into account. Figure 3 depicts the perpendicular distance of the divertor island O-points from the horizontal divertor using different planar coils currents for two coil models. Here we note that the 'as-built, EM loaded' coil model was developed for the nominal 
standard configuration with zero planar coil current. Depending on the effect of planar coil energization this estimated position of the O-point could be an upper or lower limit on the amount of transform correction needed. However, from this model we would estimate that between -750 and $-1000 A$ of planar coil current (increasing $t$ ) is necessary to bring the 'as-built, EM loaded' island chain into the correct position.

It was estimated, during operation, that a planar coil current of $-700 A$ would be necessary to compensate the reduction of rotational transform at the operational field strength of $B_{0}=2.52 T$ (on axis in the $\phi=0$ symmetry plane). These estimates were based on flux surface measurements and observations of plasma-wall interactions during operation. FEM analysis of the coils can help but requires inclusion of two important effects. First as the planar coil current becomes more negative, the non-planar coils must increase their current to maintain the desired field strength. Thus the electromagnetic loads should increase slightly. Additionally, the interaction of electromagnetic forces between the planar and non-planar coils further changes the electromagnetic loading. In practice, accounting for these effects in modeling first requires fully vetted models of the coil stiffness, still a work in progress.

In order to estimate the effect of various levels of rotational transform correction using the planar coils, magnetic field line diffusion calculations are helpful. Figure 4 depicts the effect of various levels of rotational transform correction on single strike line as computed using the FIELDLINES code (for details of the model see ref [7]). In these simulations an ensemble of $\sim 256000$ particles are initialized from a flux surface located radially inward from the divertor island chain. They are followed in both the direction parallel and anti-parallel to the magnetic field direction. Small kicks are used to simulate diffusion. The particles which collide with the divertor elements are binned along a toroidal slice ( $2^{\circ}$ in toroidal width, approximating divertor finger TM2h5 in W7$\mathrm{X})$. As the planar coil current decreases (increasing rotational transform), a clear motion of the strike line away from the pumping gap is present. For the ideal standard case (0 A planar coil current) we can see that the particle flux pattern is asymmetric which is indicative of a strike line (with peak value $\sim 13 \mathrm{~cm}$ from the pumping gap). The strike line skewness $\left(s=E(x-\mu)^{3} / \sigma^{3}\right.$, where $E$ is the expected value, $x$ the function, $\mu$ the the mean, and $\sigma$ the standard deviation) ranges linearly from around 0.8 at $0 A$ planar coil current to around 0 at $-1500 A$. Positive skewness indicates data trailing to the right, negative means trailing to the left, and zero indicates symmetric configurations. The $-1500 A$ and $-1750 A$ cases have reached a limiter-like configuration which is corroborated by the very symmetric particle flux pattern (skewness 0). The $-2000 A$ case indicates a small negative skewness $(-0.2)$. Poincaré plots indicate a transition to a limiter configuration at $-1250 \mathrm{~A}$ and a clear limiter condition by $-1500 \mathrm{~A}$. The 'Asbuilt, EM Loaded' coil model for the $0 A$ planar coil case is plotted as a shaded region. Since this configuration includes error fields, toroidal variation is present. The shaded region is bounded by the maximum and minimum values found across all ten divertors at self-similar toroidal locations. In this model, a variation in strike line locations is present but in general the strike lines appear to be shifted $\sim 4 \mathrm{~cm}$ toward the pumping 


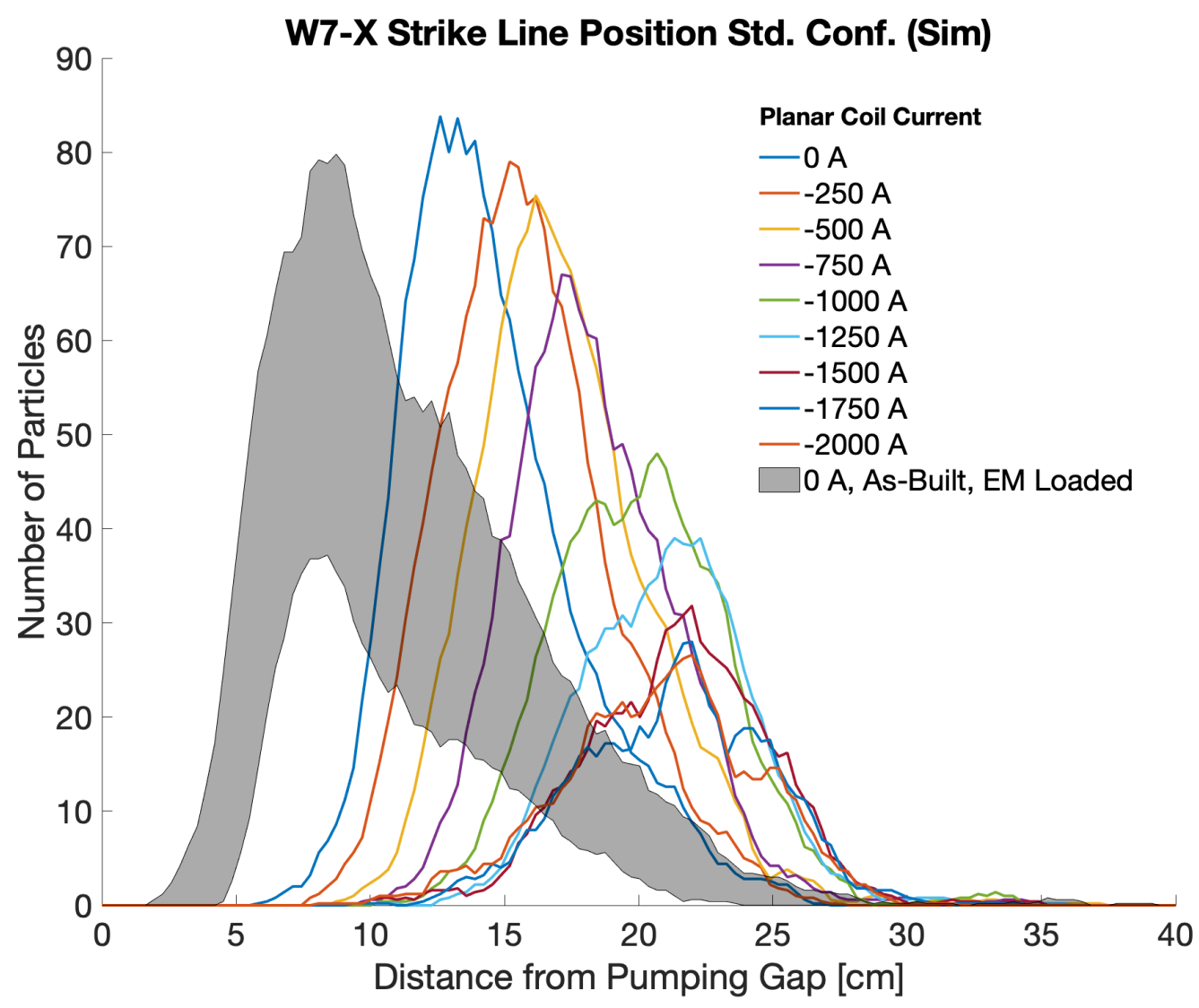

Figure 4. Field line diffusion simulations of horizontal divertor strike line using ideal coil model for the standard configuration (nominally $0 \mathrm{~A}$ in planar coils). As the planar coil currents become more negative (increasing $t$ ), the strike line move away from the pumping gap (associated with a radial motion of the island inward). Shaded region generated using the 'As-built, EM loaded' coil model for the nominal standard configuration (0 A planar coil current). Shaded region considers all 10 divertor targets. Legend indicates level of planar coil currents.

gap,as compared to the $0 A$ case. Setting the planar coil currents to $-1000 A$ causes the shaded region to bracket the $0 A$ CAD model case, suggesting this level of correction (Figure 5).

The presence of toroidal current arising from bootstrap currents, electron-cyclotron current drive, and neutral beam injection will also change strike line positions on the divertor. Here toroidal current in the plasma changes the poloidal magnetic flux resulting in changes to the location of the islands relative to the divertor plates. This effect has been measured and quantified using infrared cameras [3]. For the configurations under consideration in this paper, the effect of bootstrap current is similar to that of negative planar coil current. It raises the rotational transform at the plasma edge, thereby moving the strike lines away from the pumping gap.

The W7-X diagnostic suite includes a plunging multi-purpose manipulator (MPM) designed to accommodate multiple probe heads which can measure various scrape-off 


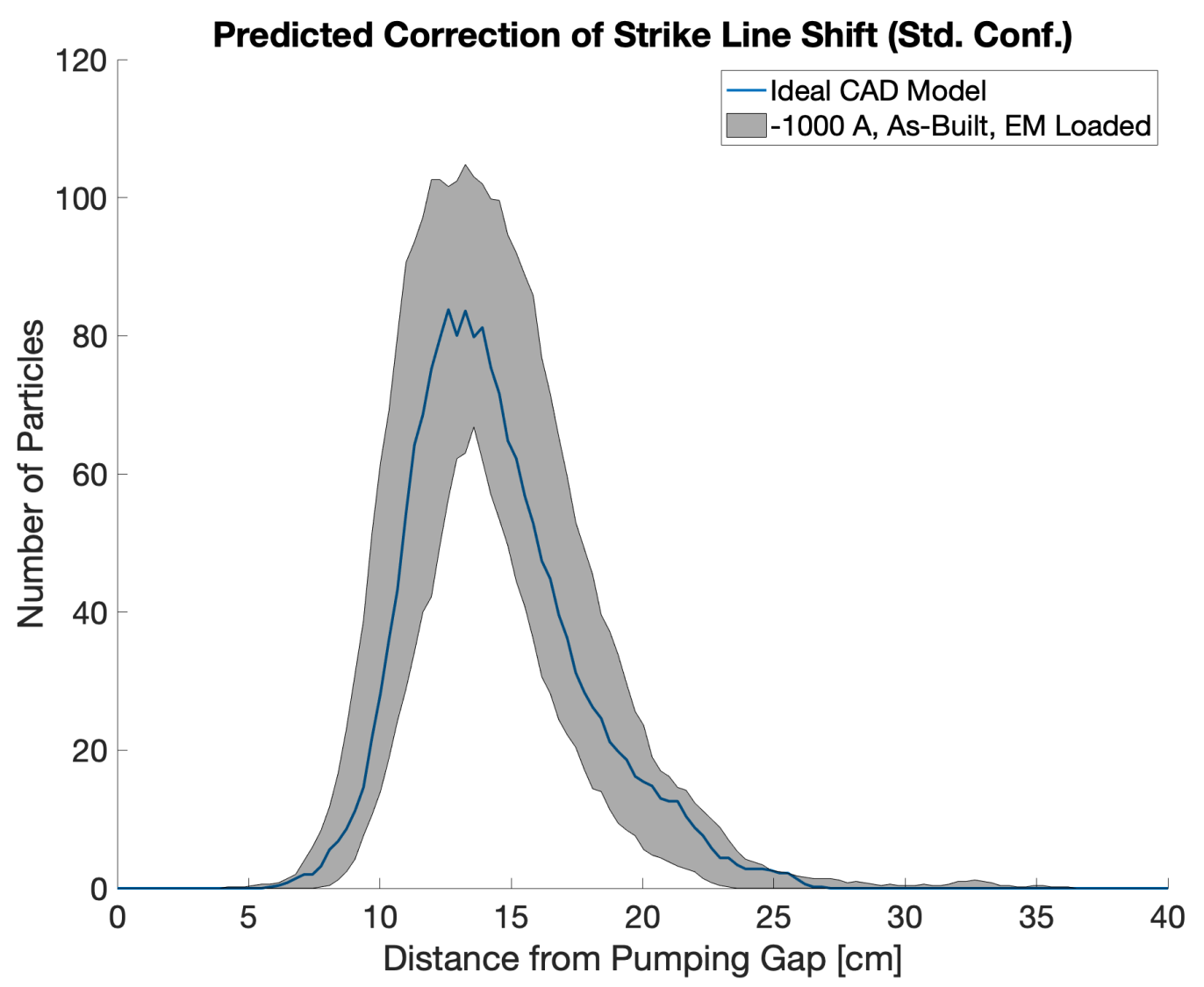

Figure 5. Field line diffusion simulations show that setting the planar coils to $-1000 \mathrm{~A}$ and using the 'As-built, EM loaded' coil model results in strike lines which bracket the nominal strike line position. Here the nominal position is defined using the CAD coil model and $0 A$ current in the planar coils.

layer quantities[19]. Figure 6 depicts modeling of field lines launched from the plunge trajectory of the MPM. In these plots red dots indicate field lines which do not intercept the divertor structure, while the black points indicates field lines within the divertor shadow. The $-2000 A$ case (right side) indicates that a significant portion of the island volume is not in the shadow of the divertor. Because the shadowed region still extends on both sides of the island chain the configuration is limiter-like. It is expected that this would provide some level of confinement in the edge region outside the core plasma. This is different from a true limiter configuration which would bound the island by flux surfaces on both sides. Specifically, a true limiter configuration would limit the plasma volume not the size of the edge island.

\section{Experimental Measurements}

In order to determine the necessary level of rotational transform correction in W7-X two experimental methods were used. The first method involved flux surface measurement of the standard configuration, while the second involved plasma discharges at similar 

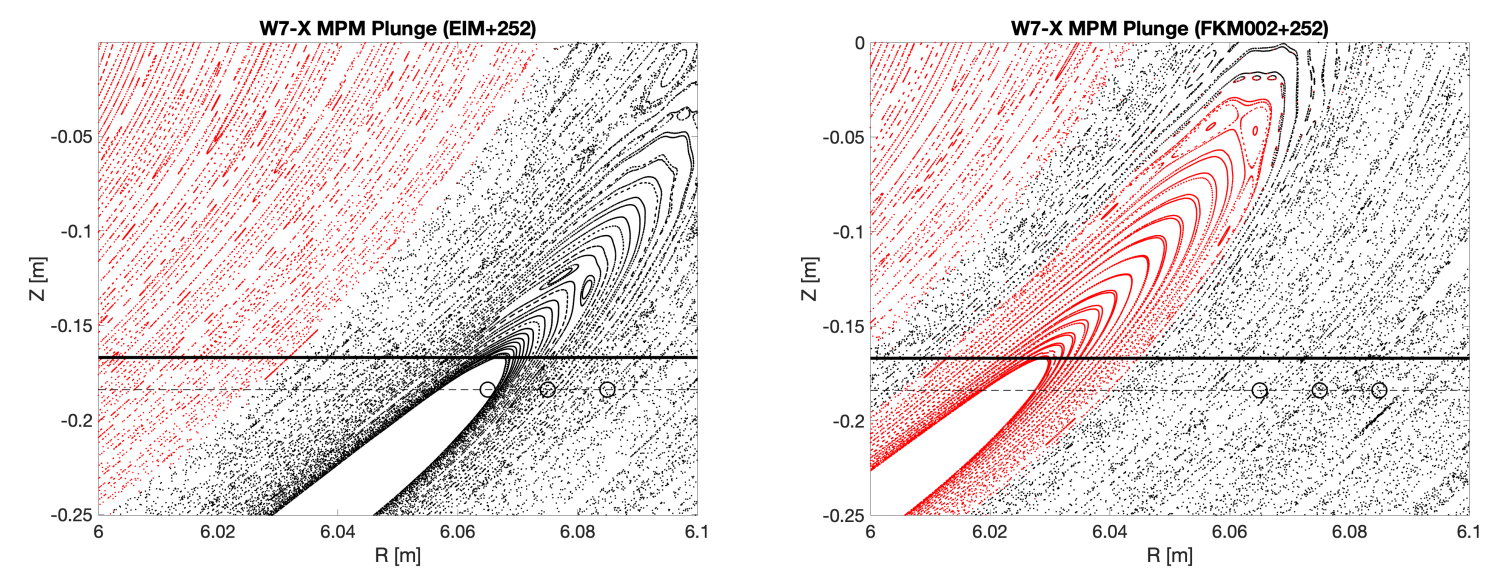

Figure 6. Vacuum Poincaré plots showing the MPM plunge trajectory with respect to the edge $n / m=5 / 5$ island chain. The standard configuration $0 A$ (EIM) is depicted on the left while the $-2000 A$ (FKM002) configuration is depicted on the right, using the ideal coil model. The solid line depicts the path of the MPM centerline, while the dashed line indicates the location of sensors on the probe head. Red points indicate field line trajectories which are not in the shadow of the divertor, while black points are in the divertor shadow. Black circles correspond to measurements presented later in figure 12 .

parameters to assess both the standard and high-mirror configuration (both of which rely on the $n / m=5 / 5$ island chain for divertor operation).

\subsection{Flux Surface Measurement}

Flux surface measurement in W7-X utilizes an electron beam emitter and a swept fluorescent rod which is imaged by a CCD camera. This allows one to create a Poincarélike image of a flux surface [16]. Unfortunately, this can only be done for surfaces which do not intersect wall structures. Thus the edge island structure of W7-X cannot be imaged when the islands are in their nominal position. However, this effect can be used to estimate the separatrix position of the configurations. This is achieved by moving the emitter to multiple locations near the edge of the configurations. The separatrix position can then be determined to lie between the last imaged edge surface and first emitter position which does not result in a flux surface trace.

Figure 7 depicts the results of just such a measurement performed over multiple values of planar coil current. A clear linear dependence of separatrix radial position on planar coil current is present. Using the measured geometry of the flux surface measurement diagnostic, an estimate can be made of the position of the ideal coil flux surface. This would suggest a value of $-100 A$ in the planar coils for iota correction. It should be noted that these measurements were performed with non-planar coil current adjustment to keep the 2.52 $\mathrm{T}$ magnetic field axis value (as needed for ECRH operation using X2 mode). While the relative position of the emitter is known to high accuracy, the absolute position comes with a large uncertainty. This is attributed to motion 


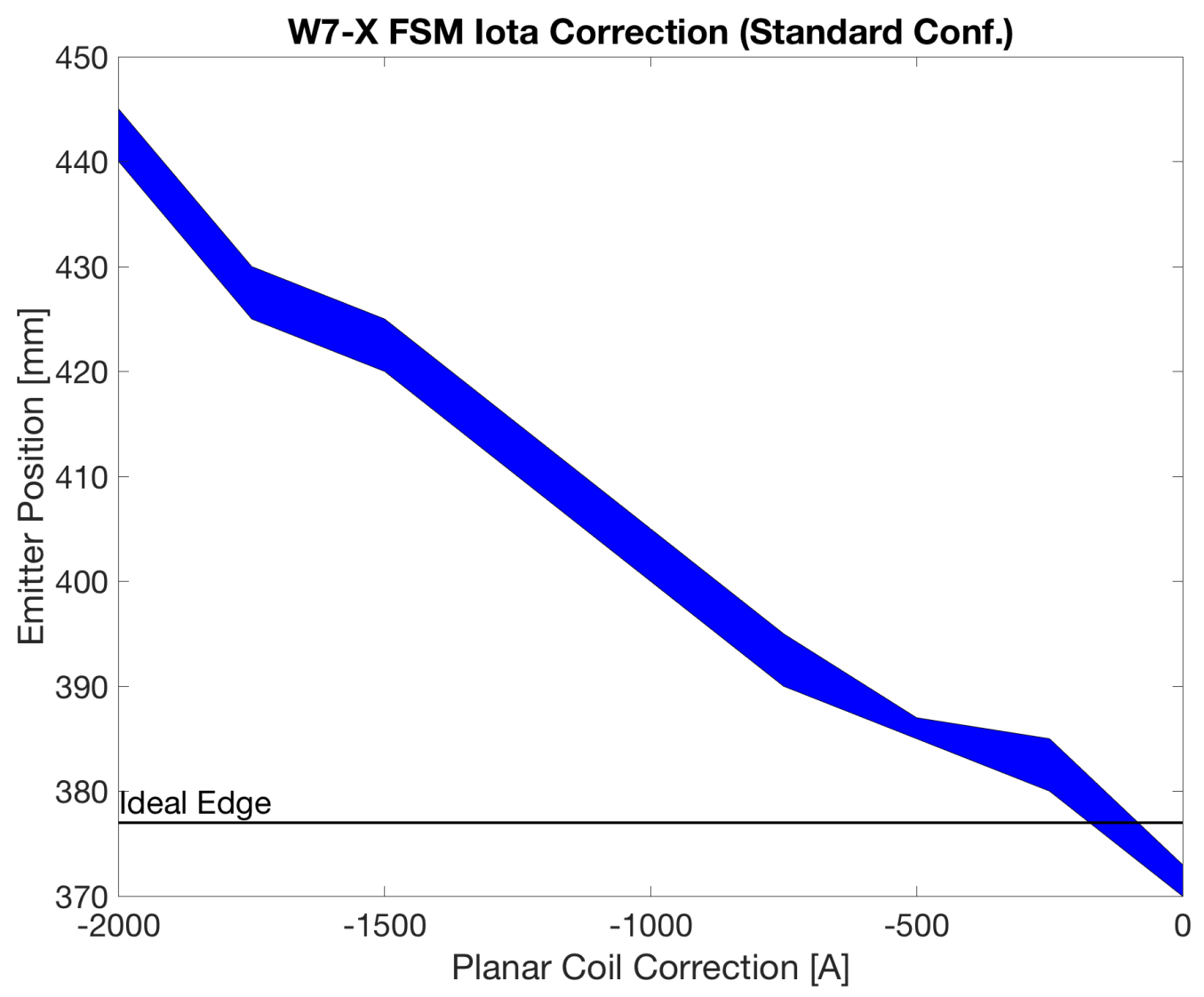

Figure 7. Separatrix radial position dependence on planar coil current as determined from flux surface measurement. Shaded region depicts separatrix location as determined by emitter position which imaged a surface and one which did not. Horizontal line indicates separatrix location as determined by field line following using the ideal coil set.

of the magnetic system relative to the emitter port as the coils are cooled down. In order to compensate for this effect, simulations are performed noting the simulated emitter position which images the last closed flux surface, and the position which images the magnetic axis. The difference in simulated emitter positions is then added to the measured emitter position which images the magnetic axis. This value is the horizontal line depicted in figure 7 , and may have up to a $\pm 1 \mathrm{~cm}$ error bar.

It is also important to note that these measurements were performed without error field correction. The emitter in only one module was used to perform these measurements. Thus the influence of error fields on these measurements could be substantial. In particular the presence of both $n / m=1 / 1$ and $n / m=2 / 2$ magnetic error fields, and their effect on the island divertor have been well documented $[15,7]$. 

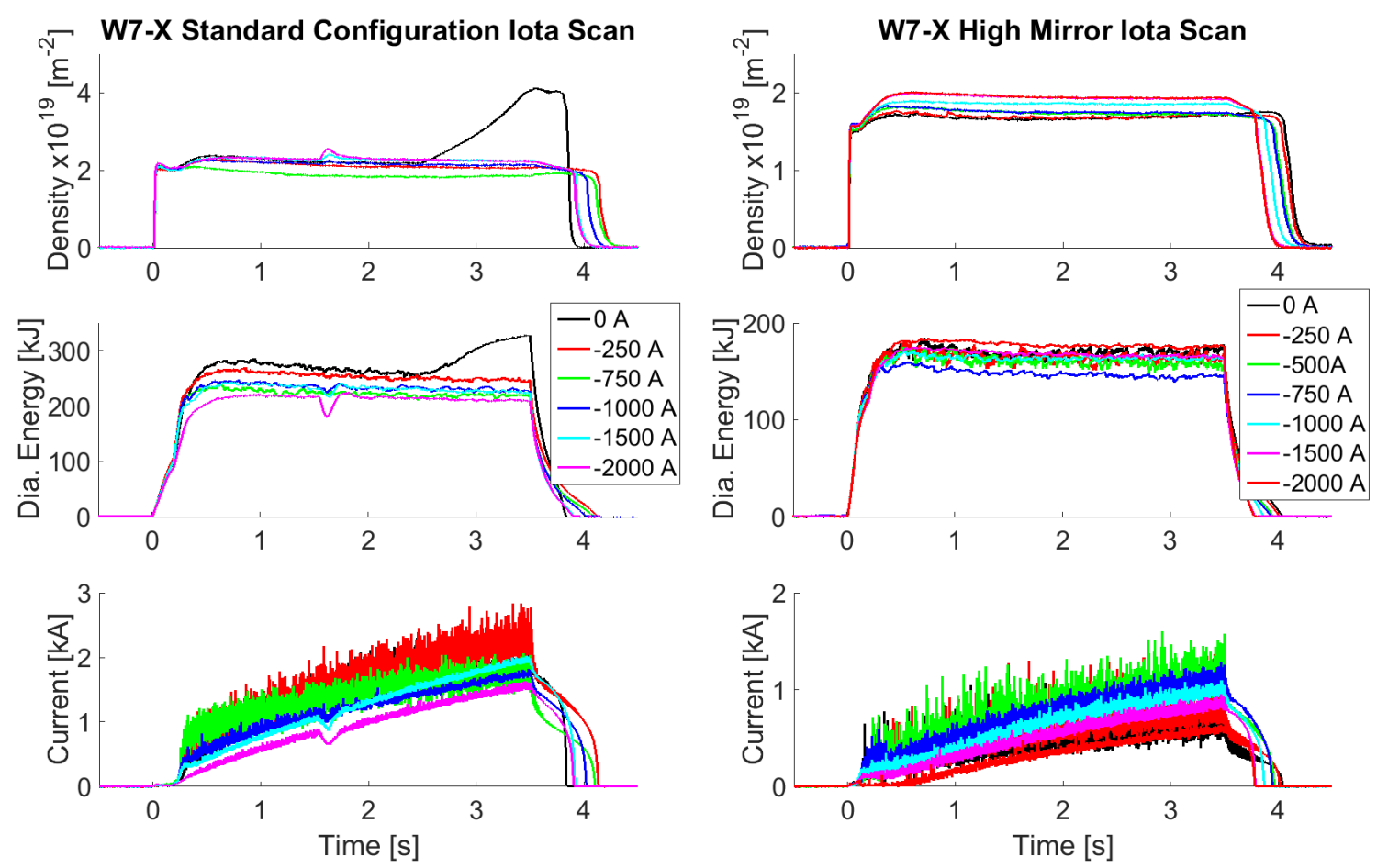

Figure 8. Overview of standard (left) and high mirror (right) configuration iota scan discharges. The first discharge indicates a loss of density control at $2.5 \mathrm{~s}$ (as measured by the interferometer [20]) associated with outgassing of the divertor but did not appear to affect heat fluxes to the divertor. A small feature at $1.7 s$ related to a plunge of the multipurpose manipulator is also present in some discharges.

\subsection{Measurements During Plasma Operation}

A set of $3.5 s, 2 M W$ ECRH, He plasma discharges were performed varying the planar coil currents in both the standard and high-mirror magnetic configurations. The standard configuration arises when all non-planar coils have the same current flowing though them and nominally no current in the planar coils. The high-mirror configuration arises when the non-planar coils have current ratios $I_{2}=0.972 I_{1}, I_{3}=0.926 I_{1}$, $I_{4}=0.880 I_{1}, I_{5}=0.852 I_{1}$ (where $I_{1}$ is the current in the first type of non-planar coil) and nominally no current in the planar coils. Figure 8 depicts the set of parameters for these discharges indicating highly reproducible plasmas which are a characteristic of stellarators in general. Note that the toroidal current is small and the toroidal current evolution for these discharges is very similar allowing us to control for the effect of plasma currents. The relatively similar levels of stored energy also allow us to control for beta effects. Planar coil currents for the discharges were $0 A,-250 A,-500 A$, $-750 A,-1000 A,-1500 A$, and $-2000 A$, where non-planar coil currents were chosen to keep $2.52 T$ at the magnetic axis in bean shaped symmetry plane (for heating).

The fluctuations in the toroidal current become smaller as the rotational transform is increased. The MPM plunge occurs at $t=1.7 \mathrm{~s}$ in the standard configuration 


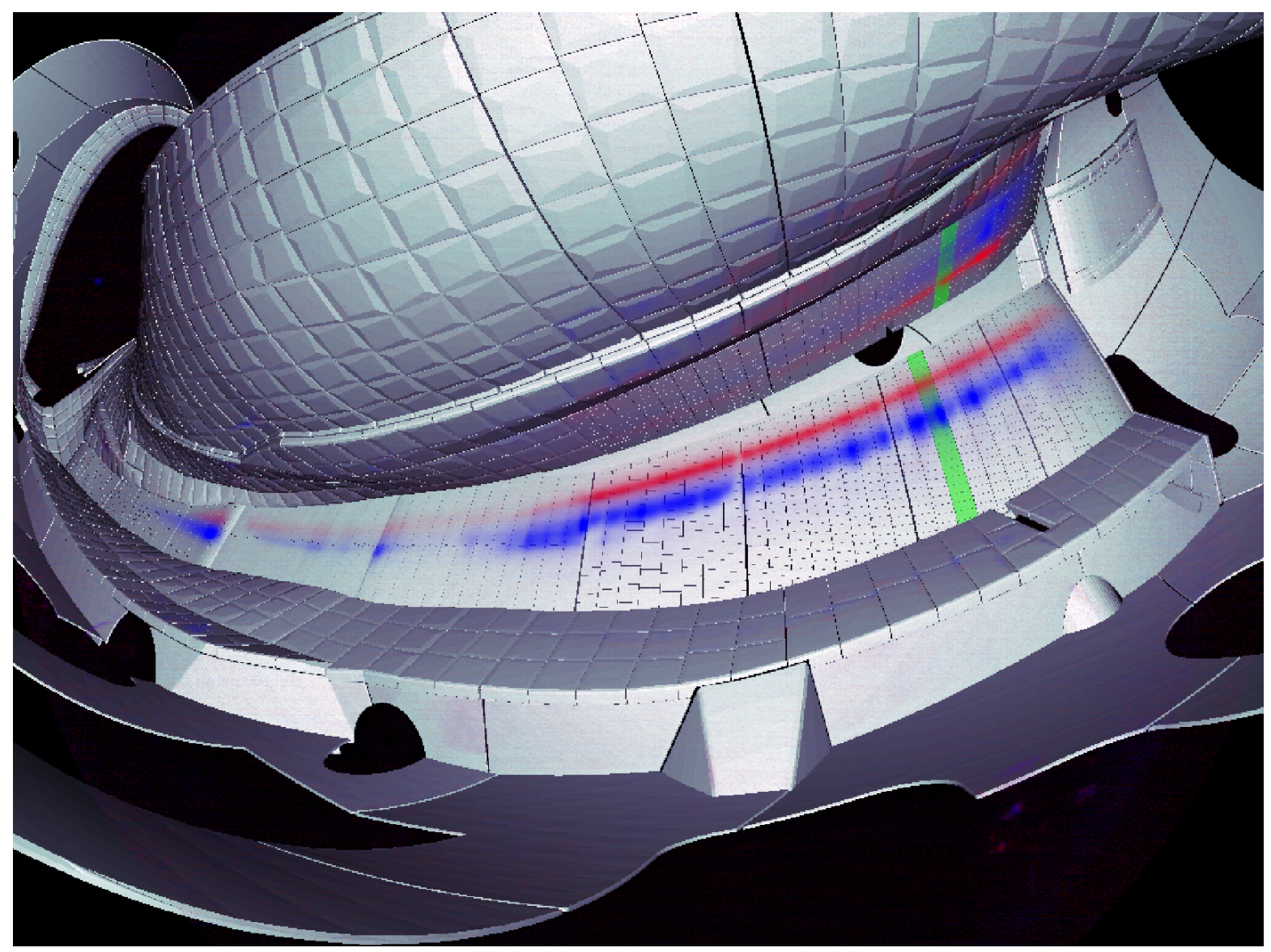

Figure 9. Projection of infrared camera data (AEF30) onto a simulated wall model showing divertor temperature rise over $3 s$ for the uncorrected (red) and $-1000 A$ (blue) standard configuration case. The divertor fingers used for strike line calculations are highlighted in green (horizontal for standard configuration, and vertical for the highmirror configuration).

and a strong perturbation in the toroidal current, diamagnetic energy and density is present for the $-1500 A$ and $-2000 A$ cases. Plunge depths were varied between shots, however the $-750 A$ and $-2000 A$ cases had similar $290 \mathrm{~mm}$ plunge depths. While not conclusive, these discharges seem to support the idea that the edge island chain has transitioned from a feature in the divertor shadow to a confining region. It also supports the hypothesis that oscillations in the toroidal current may be due to currents flowing in the scrape-off layer. The presence of a confining island in this region then somehow suppresses these oscillations.

Figure 9 depicts the change in strike line position for the standard configuration. The shift in strike line position away from the pumping gap is clearly visible on the horizontal divertor, as the planar coil current is decreased. This demonstrates the ability of the planar coils to actuate the rotational transform. A slight change in the vertical target interaction is also present. As error field correction was not present in these discharges, similar images viewing other modules show a slight variance in strike line position and amplitude of the temperature rise. However, all images indicate a motion 

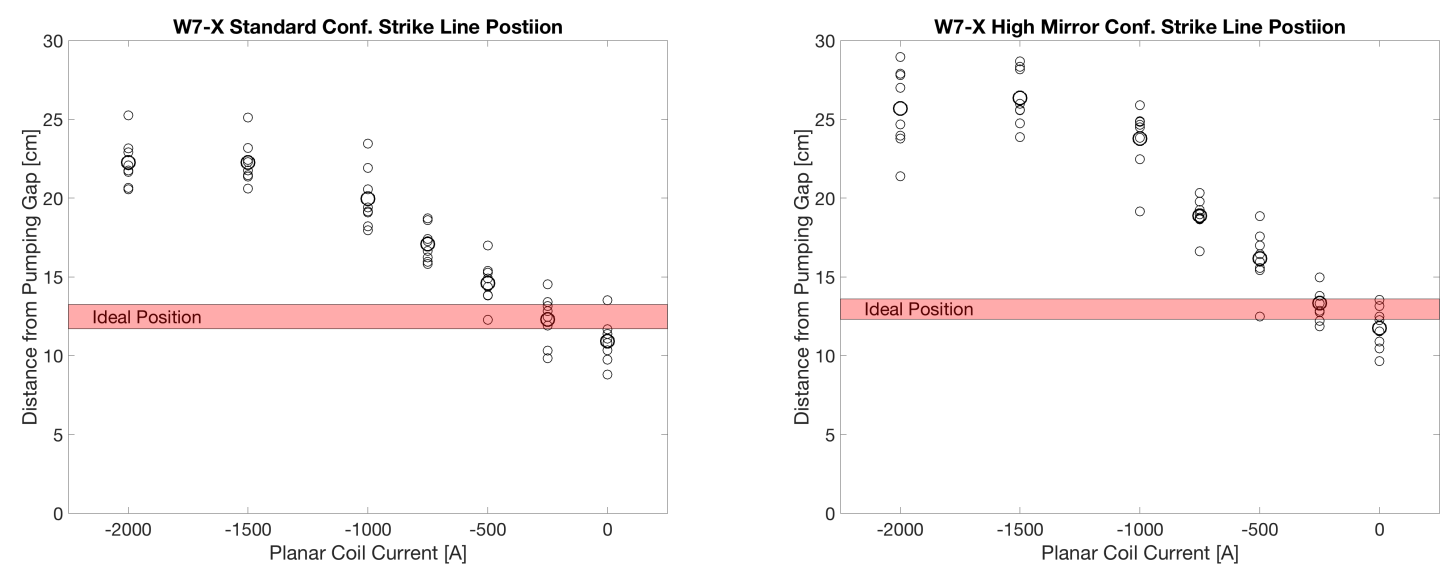

Figure 10. Strike line position as a function of planar coil currents for the standard (left) and high mirror (right) configurations. Distances are measured from the pumping gap to the peak in heat flux. Times of evaluation are chosen to control for similar values of total toroidal current across discharges. Values from every available divertor are plotted with the darker circles depicting the average value. Shaded region depicts ideal strike line location as determined by field line diffusion calculations, accounting for variations in model assumptions and interpretation.

of the strike line away from the pumping gap. While temperature rise may be used to infer strike line location, this paper used more advanced techniques [3]. The effect of toroidal current results in a maximum of $4 \mathrm{~mm}$ of shift in the strike line over a discharge. To control for this each discharge is analyzed at a time point where the toroidal current is $1 k A$ in the standard configuration and $300 \mathrm{~A}$ in the high mirror configuration. Given the stable nature of the discharges, this provides similar plasma parameters. Care is taken to avoid the density rise in the unmodified standard configuration $(0 \mathrm{~A}$ planar coil current) and the times at which the multipurpose manipulator was plunged.

The general motion of the strike lines as a function of planar coil current can be seen in figure 10. In this analysis the strike line has been defined as divertor finger 5 in the second horizontal divertor target module (depicted in green in figure 9 ). We note that beyond $-1000 A$ in the standard configuration all divertors appear to have limiter-like strike lines. This further corroborates the idea that the planar coils control rotational transform pulling the $n / m=5 / 5$ island chain radially inwards. Additionally, the $-1500 A$ and $-2000 A$ configurations have similar strike line position further corroborating the idea that the plasma has entered a limiter-like configuration. In the high-mirror magnetic configuration, we use the 10th divertor finger in the first vertical target module. The high-mirror configuration is a configuration predicted to have low neoclassical transport. It arises through a variation of the non-planar coil currents, maintaining the $n / m=5 / 5$ edge island chain. It does have a larger vertical target interaction than the standard magnetic configuration, thus motivating a focus on the vertical target for this configuration.

From this data one can estimate the level of planar coil current needed to correct 

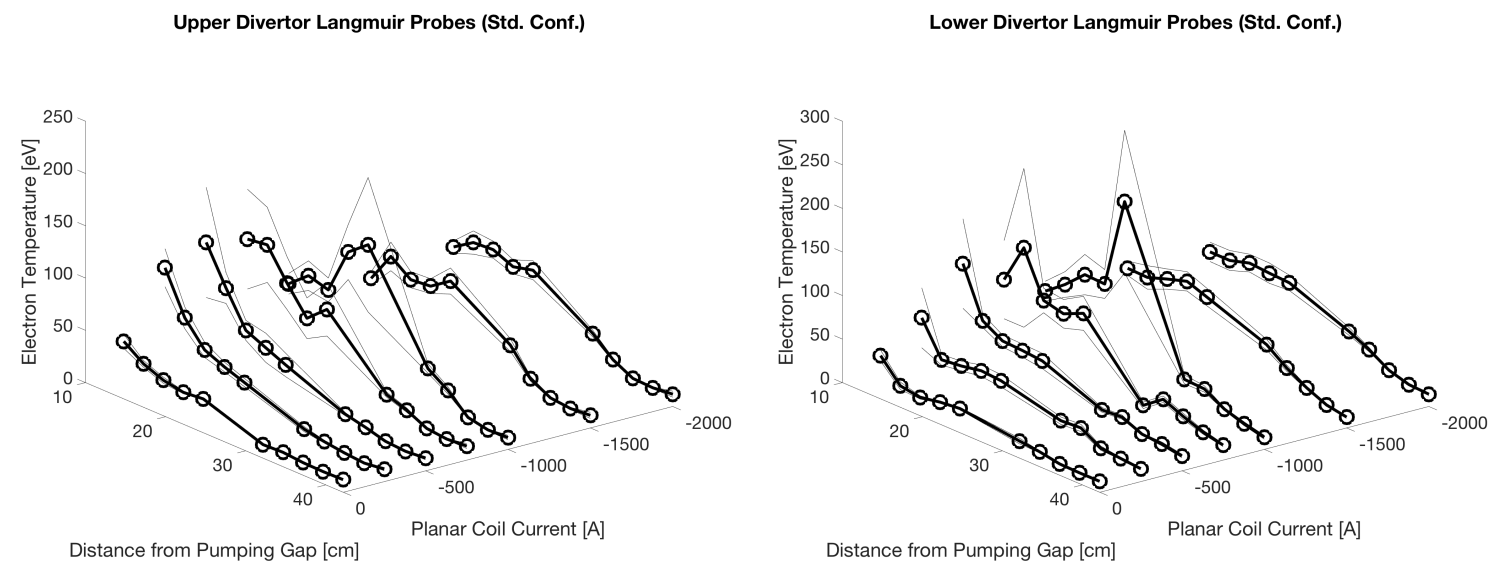

Figure 11. Electron temperature measurements from Langmuir probes embedded in the module 5 upper and lower divertor for the standard magnetic configuration. The peak in electron temperature moves away from the pumping gap as planar coil current is increased. Cases with limiter-like configurations show no strong peak. Thin lines indicate extent of errors, circles indicate probe location.

for divertor strike line position. Field line diffusion simulations using the ideal magnetic coils and divertor placement suggest that in the standard configuration the peak of the divertor strike line sits $\sim 13 \mathrm{~cm}$ from the pumping gap. In the high mirror configuration loads are predominantly on the vertical target. Here simulation data suggests an ideal positioning of the strike line $\sim 14 \mathrm{~cm}$ from the pumping gap. Experimental data would then suggest between -250 and $-500 A$ of planar coil correction in the standard configuration and around $-250 \mathrm{~A}$ of correction in the high mirror configuration. The discrepancy between configurations can be related to the fact that in the standard configuration all non-planar coils have the same current flowing in them while the high-mirror configuration has differing currents in each non-planar coil type. Thus the electromagnetic loading of the configurations is significantly different. Accounting for toroidal currents it can be seen that the level of correction for both configurations falls between $-250 \mathrm{~A}$ and $0 \mathrm{~A}$ of planar coil current.

Two of the divertor modules possess a set of flush mounted Langmuir probes. These probes allow for measurement of electron density and temperature in the scrape-off layer of the plasma. Figure 11 depicts the effect of the planar coil current scan on the measured electron temperature. The location of the electron temperature peak roughly correlates with the position of the strike line as measured with the infrared cameras. The $-1500 \mathrm{~A}$ and $-2000 A$ cases appear to have similar profiles and strike line locations which is also consistent with the infrared camera data. It is clear from this data that the strike line is not located within the Langmuir probe array for the uncorrected case and $-250 \mathrm{~A}$ cases. While not obvious, there is a trend in the peak of the electron temperature to move away from the pumping gap as the rotational transform increases (planar coil current decreases). Unfortunately the array does not straddle the nominal strike line location (13 $\mathrm{cm}$ from the pumping gap). Thus it is difficult to estimate the level of 


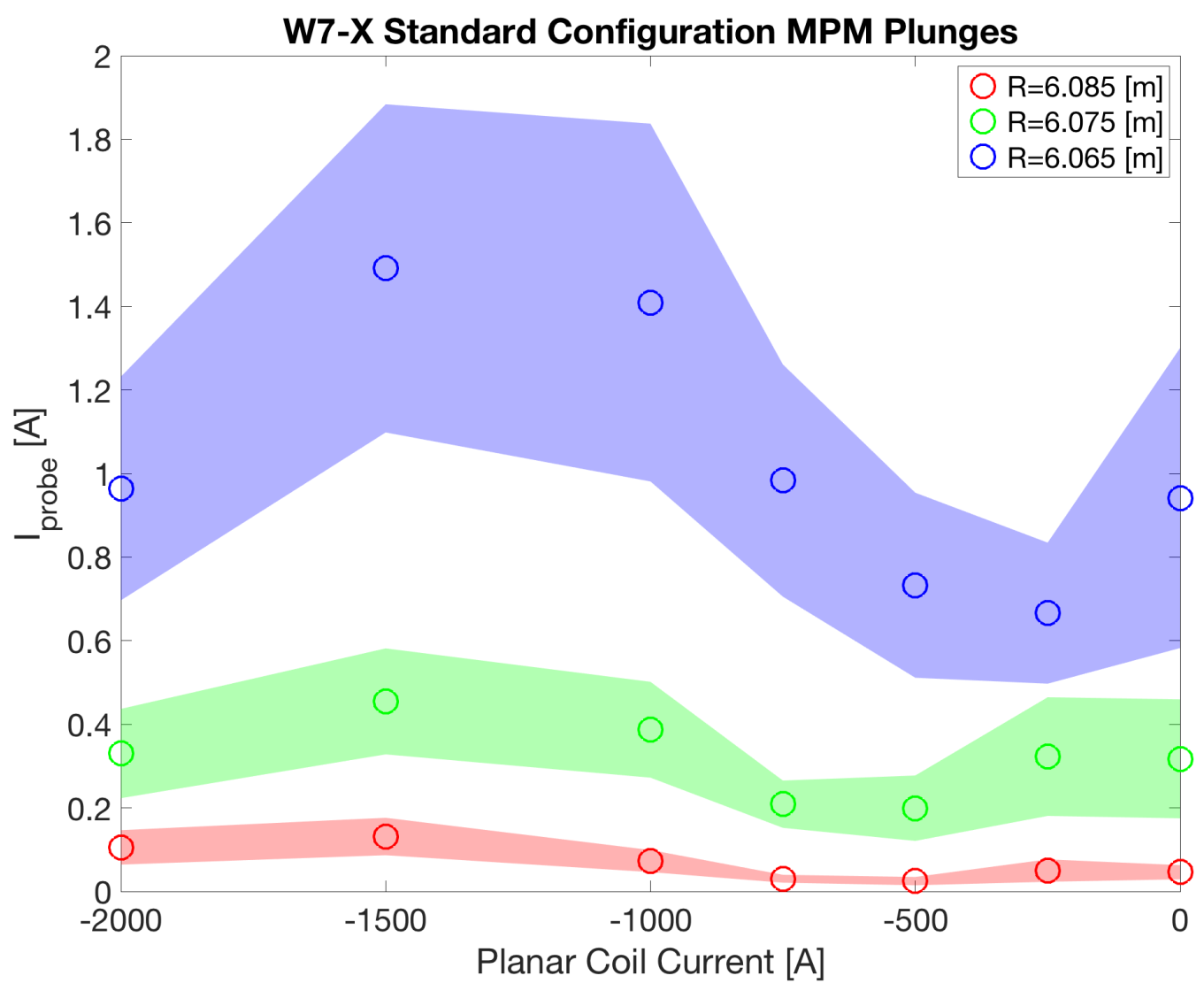

Figure 12. Probe current as measured by multi-purpose manipulator at three plunge depths. Here $I_{\text {probe }}$ is roughly proportional to density and $R \sim 6.035 \mathrm{~m}$ would correspond to the flux surface just inside the island chain (in real coordinates). Shaded region depicts the standard deviation of the signal.

transform correction necessary from this diagnostic alone. However, one can say that less than $-750 A$ of corrections is necessary, since the peak in electron temperature (lower divertor) is approximately located at $\sim 17.5 \mathrm{~cm}$ for that discharge.

Figure 12 depicts the measured current of a negatively biased probe $\left(I_{\text {probe }}\right)$ on the MPM probe head [19, 21]. As the rotational transform is increased, the probe current increases while the bulk plasma density does not change (as measured by the interferometer). This suggests that the confinement in the region outside the equilibrium last closed flux surface has improved (assuming probe current is proportional to plasma density). As the transform is increased, Poincaré plots suggest an increase in the island volume which is no longer in the divertor shadow (located at the center of the island). Increased probe current also suggests that the density in the island may be increasing. It should be noted that similar experiments performed during the first limiter campaign found a similar effect, although the scan performed changed both the edge transform and radial plasma position [22].

The hypothesis that the island is confining plasma for the $-2000 \mathrm{~A}$ case is confirmed 


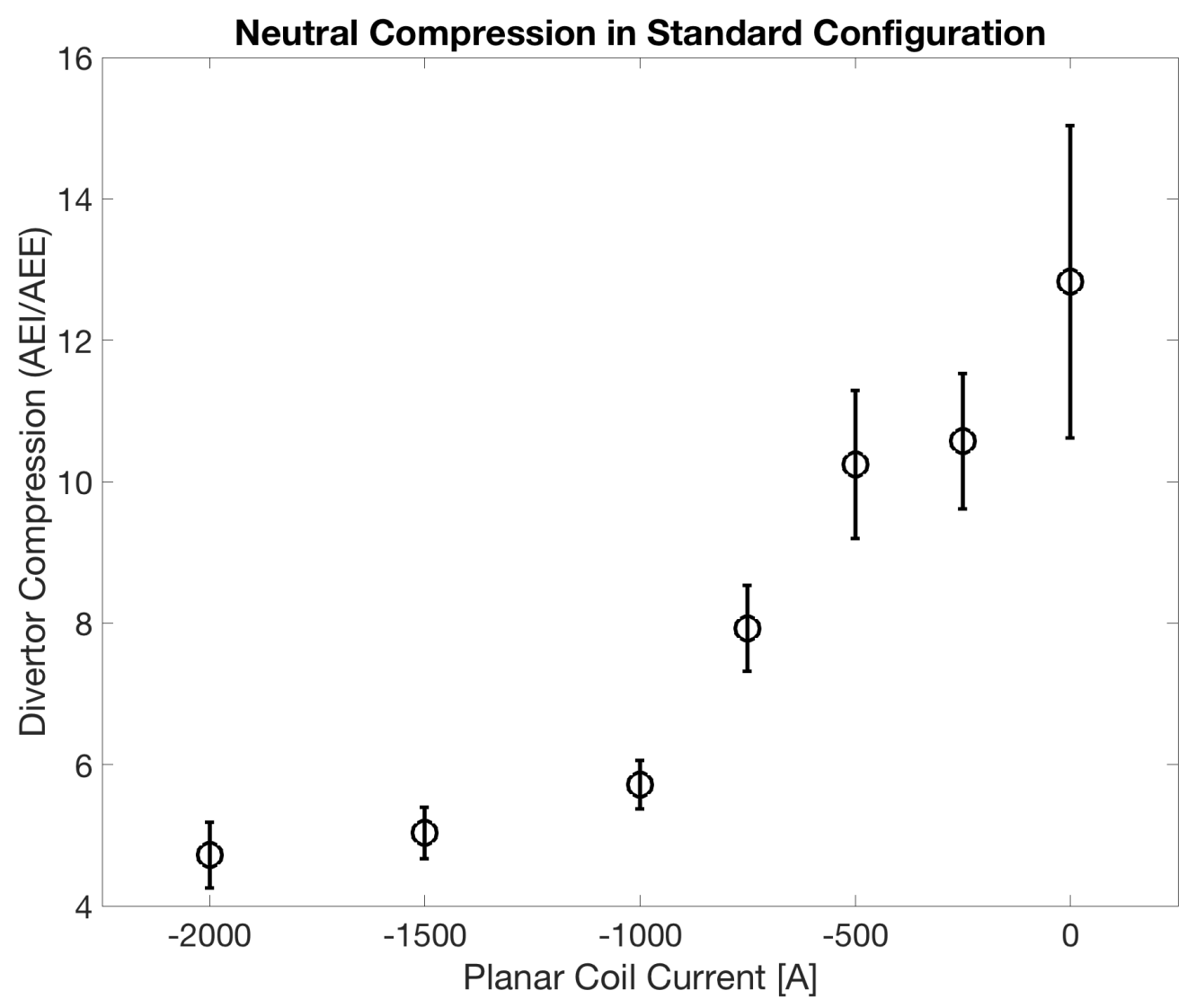

Figure 13. Neutral compression as measured by neutral gas manometers at the outboard (AEE) and divertor ports (AEI). A clear decrease in the neutral compression is seen as strike lines move away from the divertor and become limiter-like.

by figure 8 , where we see a decrease in the diamagnetic energy and an increase in density as the probe is plunged at around $t=1.6 \mathrm{~s}$ into the discharge. Here the manipulator was far from the vacuum last closed flux surface. It is likely that in these discharges the island was being limited by the manipulator head as it plunged. This is confirmed by visible camera images which show a very bright light emission from the probe head, resulting in saturated images.

The effect of these changes on the divertor performance can be seen in measurements made by the neutral gas manometer system in W7-X [23]. Figure 13 indicates that as the planar coil currents became more negative, causing the strike lines to move away from the pumping gap, the compression ratio decreased. This is consistent with the notion that moving strike lines away from the pumping gap decreases divertor pumping. Additionally, we see that by $-1000 A$ the neutral compression appears to have reduced by a factor of two and becomes nearly constant as the planar coil current is further decreased. This change in neutral compression is attributed to significant decreases in the divertor pressure over the scan (from $\sim 2.5 \times 10^{-5} \mathrm{mBar}$ to $\sim 1.4 \times 10^{-5} \mathrm{mBar}$ ), while mid-plane pressure only increased slightly (from $\sim$ 
$2 \times 10^{-6} \mathrm{mBar}$ to $\left.\sim 3 \times 10^{-6} \mathrm{mBar}\right)$. We postulate that, as the strike line moves outward fewer neutrals reach the sub-divertor space and instead end up at the midplane. It should be noted that these measurements were performed in helium fueled plasmas, before boronization. After boronization the divertor compression significantly increased with around $-750 \mathrm{~A}$ of planar coil current [24].

\section{Discussion}

The planar superconducting coil set of Wendelstein 7-X has been used to demonstrate both the active control of rotational transform and the correction of electromagnetic load effects on rotational transform. Such correction has been validated through flux surface mapping of the plasma last closed flux surface and divertor strike line positioning. These two methods suggest a small level of rotational transform correction between 0 and $-250 \mathrm{~A}$, once toroidal current is accounted for [25]. Additionally, divertor Langmuir probe measurements from the divertor and the multi-purpose manipulator measurements confirm these findings. It should be noted that detailed analysis was not possible during the experimental campaign and planar coil currents between -500 and $-750 A$ were nominally used. This avoided the 'Abschirmhaus' interaction which motivated initial attempts at rotational transform active control.

These experiments were performed before error field correction could be applied. This influences the strike line position and plays a strong role in the interpretation of the MPM data. In particular, different diagnostics measure quantities in different locations over a field period, and in different modules. Additionally, these were helium discharges carried out before boronization of the device (which clearly had a strong effect on divertor performance). In future experiments, error field correction should be applied for all discharges. A refined and expanded scan would include planar coil currents of $-1000,-750,-500,-250,0,250,500,750$, and $1000 A$. The inclusion of positive planar coils currents would move the strike lines toward the pumping gap. Coupled with the pumping gap cryo-pumps (to be installed in the next campaign), such experiments would allow us to better characterize the pumping efficiency as a function of strike line location. Additionally, one may want to revisit the $-2000 A$ case with a more commissioned set of diagnostics to better understand the role the island is playing when moved out of the divertor shadow but not into the main plasma confinement region.

While the planar coil system of W7-X provides the necessary magnetic configuration flexibility for rotational transform correction, such coils are not usually considered in a stellarator reactor design. Coil design for reactors usually focuses on minimizing coil complexity and maximizing access for blanket maintenance. In this sense, the planar coils of W7-X are not a desirable design choice for a reactor. The difficulties encountered in the port design for the neutral beam injection system typify the difficulties such coils present with respect to port design [26]. However, the deformation of non-planar coils under electromagnetic load and subsequent iota reduction are an even larger issue at the higher fields and stresses in reactor designs. This is especially true of the Helias line 
of reactors which rely solely on non-planar modular coils. Additionally, the utility of rotational transform control using an interplay between stellarator coils, toroidal field coils, and plasma current has been demonstrated as useful for exploring turbulence in stellarators [27].

\section{Acknowledgments}

The authors would like to thank V. Bykov for our useful discussions. This work has been carried out within the framework of the EUROfusion Consortium and has received funding from the Euratom research and training programme 2014-2018 and 2019-2020 under grant agreement No 633053. The views and opinions expressed herein do not necessarily reflect those of the European Commission.

[1] Joachim Geiger, Craig D Beidler, M Drevlak, Henning Maaßberg, Carolin Nührenberg, Yasuhiro Suzuki, and Y Turkin. Effects of Net Currents on the Magnetic Configuration of W7-X. Contributions to Plasma Physics, 50(8):770-774, July 2010.

[2] A Dinklage, Craig D Beidler, P Helander, G Fuchert, H. Maaßberg, K. Rahbarnia, T. Sunn Pedersen, Y Turkin, Robert C Wolf, A Alonso, Tamara Andreeva, Boyd D Blackwell, Sergey A Bozhenkov, B. Buttenschön, A Czarnecka, F Effenberg, Y Feng, Joachim Geiger, M Hirsch, U. Höfel, M. Jakubowski, T. Klinger, J. Knauer, G. Kocsis, A. Krämer-Flecken, M. Kubkowska, A Langenberg, H P Laqua, N Marushchenko, A Mollén n, U Neuner, H Niemann, E Pasch, N Pablant, L Rudischhauser, H M Smith, O Schmitz, T Stange, T Szepesi, G Weir, T Windisch, G A Wurden, Zhang, and the W7-X Team. Magnetic configuration effects on the Wendelstein 7-X stellarator. Nature Physics, pages 1-10, September 2018.

[3] Y. Gao, Marcin W. Jakubowski, Peter Drewelow, Fabio Pisano, Aleix Puig Sitjes, Holger Niemann, Adnan Ali, and Barbara Cannas and. Methods for quantitative study of divertor heat loads on w7-x. Nuclear Fusion, 59(6):066007, apr 2019.

[4] A Lumsdaine, J Tipton, J Lore, D McGinnis, J M Canik, J Harris, A Peacock, J Boscary, J Tretter, and Tamara Andreeva. Design and analysis of the W7-X divertor scraper element. Fusion Engineering and Design, 88(9-10):1773-1777, October 2013.

[5] Y Turkin, Henning Maaßberg, Craig D Beidler, Joachim Geiger, and N B Marushchenko. Current control by ECCD for W7-X. Fusion Science and Technology, 50(3):387-394, 2006.

[6] Samuel Lazerson, Matthias Otte, Sergey A Bozhenkov, Christoph Biedermann, Thomas Sunn Pedersen, and the W7-X Team. First measurements of error fields on W7-X using flux surface mapping. Nuclear Fusion, 56(10):106005, August 2016.

[7] Samuel Lazerson, Sergey A Bozhenkov, Ben Israeli, Matthias Otte, Holger Niemann, Victor Bykov, Michael Endler, Tamara Andreeva, Adnan Ali, Peter Drewelow, Marcin Jakubowski, Aleix Puig Sitjes, Fabio Pisano, Barbara Cannas, and the W7-X Team. Error fields in the Wendelstein 7-X stellarator. Plasma Physics and Controlled Fusion, 60(12):124002-12, November 2018.

[8] Sergey A Bozhenkov, Joachim Geiger, M Grahl, Johann Kisslinger, A Werner, and Robert C Wolf. Service oriented architecture for scientific analysis at W7-X. An example of a field line tracer. Fusion Engineering and Design, 88(11):2997-3006, November 2013.

[9] Tamara Andreeva, T Bräuer, M Endler, Johann Kisslinger, and U v Toussaint. Influence of construction errors on Wendelstein 7-X magnetic configurations. Fusion Engineering and Design, 84(2-6):408-412, June 2009.

[10] Joris Fellinger, Konstantin Egorov, Johannes Peter Kallmeyer, Victor Bykov, and Felix Schauer. Fusion Engineering and Design. Fusion Engineering and Design, 89(9-10):2189-2193, October 2014.

[11] Thomas Sunn Pedersen, Matthias Otte, Samuel Lazerson, Per Helander, Sergey A Bozhenkov, Christoph Biedermann, T Klinger, Robert C Wolf, and H S Bosch. Confirmation of the topology 
of the Wendelstein 7-X magnetic field to better than 1: 100,000. Nature Communications, 7, 2016.

[12] Sergey A Bozhenkov, M W Jakubowski, H Niemann, Samuel Lazerson, G A Wurden, C Biedermann, G Kocsis, R König, F Pisano, L A Stephey, T Szepesi, U Wenzel, Thomas Sunn Pedersen, Robert C Wolf, and W7-X Team. Effect of error field correction coils on W7-X limiter loads. Nuclear Fusion, 57(12):126030-11, September 2017.

[13] Samuel Lazerson, Matthias Otte, Marcin Jakubowski, Ben Israeli, Glen A Wurden, Uwe Wenzel, Tamara Andreeva, Sergey A Bozhenkov, Christoph Biedermann, Gabor Kocsis, Tamas Szepesi, Joachim Geiger, Thomas Sunn Pedersen, David Gates, and the W7-X Team. Error field measurement, correction and heat flux balancing on Wendelstein 7-X. Nuclear Fusion, 57(4):046026-9, March 2017.

[14] Sergey A Bozhenkov, Samuel Lazerson, Matthias Otte, David A Gates, Thomas Sunn Pedersen, and Robert C Wolf. Methods for measuring 1/1 error field in Wendelstein 7-X stellarator. Nuclear Fusion, page 076002, June 2016.

[15] S.A. Bozhenkov, M. Otte, C. Biedermann, M. Jakubowski, S.A. Lazerson, T. Sunn Pedersen, and R.C. Wolf and. Measurements and correction of the $1 / 1$ error field in wendelstein 7-x. Nuclear Fusion, 59(2):026004, dec 2018.

[16] Matthias Otte, D Aßmus, C Biedermann, Sergey A Bozhenkov, T Bräuer, A Dudek, Joachim Geiger, G Kocsis, Samuel Lazerson, Thomas Sunn Pedersen, F Schauer, T Szepesi, B Standley, and the W7-X Team. Setup and initial results from the magneticflux surface diagnostics at Wendelstein 7-X. Plasma Physics and Controlled Fusion, 58(06):064003, May 2016.

[17] Victor Bykov, Jiawu Zhu, Andre Carls, Ilia Ivashov, Joachim Geiger, Bernd Hein, Hans-Stephan Bosch, and Lutz Wegener. Engineering Challenges of Wendelstein 7-X Mechanical Monitoring During Second Phase of Operation. Fusion Science and Technology, 00(00):1-10, June 2019.

[18] Victor Bykov, Joris Fellinger, Felix Schauer, Andre Carls, Matthias Koppen, Paul van Eeten, Hans-Stephan Bosch, Lutz Wegener, and Jiawu Zhu. Structural Analysis at the Transition From W7-X Construction to Operation. IEEE Transactions on Plasma Science, 44(1):17221730, August 2016.

[19] D Nicolai, V Borsuk, P Drews, O Grulke, K P Hollfeld, T Krings, Y Liang, Ch Linsmeier, O Neubauer, G Satheeswaran, B Schweer, G Offermanns, and the W7-X Team. A multi-purpose manipulator system for W7-X as user facility for plasma edge investigation. Fusion Engineering and Design, 123:960-964, November 2017.

[20] K.J. Brunner, T. Akiyama, M. Hirsch, J. Knauer, P. Kornejew, B. Kursinski, H. Laqua, J. Meineke, H. Trimiño Mora, and R. C. Wolf. Real-time dispersion interferometry for density feedback in fusion devices. Journal of Instrumentation, 13(09):P09002-P09002, Sep 2018.

[21] Piero Agostinetti, Monica Spolaore, Matteo Brombin, Vannino Cervaro, Luca Franchin, Olaf Grulke, Carsten Killer, Emilio Martines, Maurizio Moresco, Simone Peruzzo, Nicola Vianello, and Michele Visentin. Design of a High Resolution Probe Head for Electromagnetic Turbulence Investigations in W7-X. IEEE Transactions on Plasma Science, 46(1):1306-1311, May 2018.

[22] P Drews, Y Liang, S Liu, A Kramer-Flecken, O Neubauer, Joachim Geiger, M Rack, D Nicolai, O Grulke, C Killer, N Wang, A Charl, B Schweer, P Denner, M Henkel, Y Gao, K Hollfeld, G Satheeswaran, N Sandri, D Höschen, and the W7-X Team. Measurement of the plasma edge profiles using the combined probe on W7-X. Nuclear Fusion, 57(12):126020-9, September 2017.

[23] U Wenzel, T Kremeyer, G Schlisio, M Marquardt, Thomas Sunn Pedersen, O Schmitz, B Mackie, $\mathrm{J}$ Maisano-Brown, and the W7-X Team. Advanced neutral gas diagnostics for magnetic confinement devices. Journal of Instrumentation, 12(09):C09008-C09008, September 2017.

[24] T. Klinger, T. Andreeva, S. Bozhenkov, C. Brandt, R. Burhenn, B. Buttenschön, G. Fuchert, B. Geiger, O. Grulke, H.P. Laqua, N. Pablant, K. Rahbarnia, T. Stange, A. von Stechow, N. Tamura, H. Thomsen, Y. Turkin, T. Wegner, I. Abramovic, S. Äkäslompolo, J. Alcuson, P. Aleynikov, K. Aleynikova, A. Ali, A. Alonso, G. Anda, E. Ascasibar, J.P. Bähner, S.G. Baek, M. Balden, J. Baldzuhn, M. Banduch, T. Barbui, W. Behr, C. Beidler, A. Benndorf, 
C. Biedermann, W. Biel, B. Blackwell, E. Blanco, M. Blatzheim, S. Ballinger, T. Bluhm, D. Böckenhoff, B. Böswirth, L.-G. Böttger, M. Borchardt, V. Borsuk, J. Boscary, H.-S. Bosch, M. Beurskens, R. Brakel, H. Brand, T. Bräuer, H. Braune, S. Brezinsek, K.-J. Brunner, R. Bussiahn, V. Bykov, J. Cai, I. Calvo, B. Cannas, A. Cappa, A. Carls, D. Carralero, L. Carraro, B. Carvalho, F. Castejon, A. Charl, N. Chaudhary, D. Chauvin, F. Chernyshev, M. Cianciosa, R. Citarella, G. Claps, J. Coenen, M. Cole, M.J. Cole, F. Cordella, G. Cseh, A. Czarnecka, K. Czerski, M. Czerwinski, G. Czymek, A. da Molin, A. da Silva, H. Damm, A. de la Pena, S. Degenkolbe, C.P. Dhard, M. Dibon, A. Dinklage, T. Dittmar, M. Drevlak, P. Drewelow, P. Drews, F. Durodie, E. Edlund, P. van Eeten, F. Effenberg, G. Ehrke, S. Elgeti, M. Endler, D. Ennis, H. Esteban, T. Estrada, J. Fellinger, Y. Feng, E. Flom, H. Fernandes, W.H. Fietz, W. Figacz, J. Fontdecaba, O. Ford, T. Fornal, H. Frerichs, A. Freund, T. Funaba, A. Galkowski, G. Gantenbein, Y. Gao, J. García Regaña, D. Gates, J. Geiger, V. Giannella, A. Gogoleva, B. Goncalves, A. Goriaev, D. Gradic, M. Grahl, J. Green, H. Greuner, A. Grosman, H. Grote, M. Gruca, C. Guerard, P. Hacker, X. Han, J.H. Harris, D. Hartmann, D. Hathiramani, B. Hein, B. Heinemann, P. Helander, S. Henneberg, M. Henkel, J. Hernandez Sanchez, C. Hidalgo, M. Hirsch, K.P. Hollfeld, U. Höfel, A. Hölting, D. Höschen, M. Houry, J. Howard, X. Huang, Z. Huang, M. Hubeny, M. Huber, H. Hunger, K. Ida, T. Ilkei, S. Illy, B. Israeli, S. Jablonski, M. Jakubowski, J. Jelonnek, H. Jenzsch, T. Jesche, M. Jia, P. Junghanns, J. Kacmarczyk, J.-P. Kallmeyer, U. Kamionka, H. Kasahara, W. Kasparek, Y.O. Kazakov, N. Kenmochi, C. Killer, A. Kirschner, R. Kleiber, J. Knauer, M. Knaup, A. Knieps, T. Kobarg, G. Kocsis, F. Köchl, Y. Kolesnichenko, A. Könies, R. König, P. Kornejew, J.-P. Koschinsky, F. Köster, M. Krämer, R. Krampitz, A. Krämer-Flecken, N. Krawczyk, T. Kremeyer, J. Krom, M. Krychowiak, I. Ksiazek, M. Kubkowska, G. Kühner, T. KurkiSuonio, P.A. Kurz, S. Kwak, M. Landreman, P. Lang, R. Lang, A. Langenberg, S. Langish, H. Laqua, R. Laube, S. Lazerson, C. Lechte, M. Lennartz, W. Leonhardt, C. Li, C. Li, Y. Li, Y. Liang, C. Linsmeier, S. Liu, J.-F. Lobsien, D. Loesser, J. Loizu Cisquella, J. Lore, A. Lorenz, M. Losert, A. Lücke, A. Lumsdaine, V. Lutsenko, H. Maaßberg, O. Marchuk, J.H. Matthew, S. Marsen, M. Marushchenko, S. Masuzaki, D. Maurer, M. Mayer, K. McCarthy, P. McNeely, A. Meier, D. Mellein, B. Mendelevitch, P. Mertens, D. Mikkelsen, A. Mishchenko, B. Missal, J. Mittelstaedt, T. Mizuuchi, A. Mollen, V. Moncada, T. Mönnich, T. Morisaki, D. Moseev, S. Murakami, G. Náfrádi, M. Nagel, D. Naujoks, H. Neilson, R. Neu, O. Neubauer, U. Neuner, T. Ngo, D. Nicolai, S.K. Nielsen, H. Niemann, T. Nishizawa, R. Nocentini, C. Nührenberg, J. Nührenberg, S. Obermayer, G. Offermanns, K. Ogawa, J. Ölmanns, J. Ongena, J.W. Oosterbeek, G. Orozco, M. Otte, L. Pacios Rodriguez, N. Panadero, N. Panadero Alvarez, D. Papenfuß, S. Paqay, E. Pasch, A. Pavone, E. Pawelec, T.S. Pedersen, G. Pelka, V. Perseo, B. Peterson, D. Pilopp, S. Pingel, F. Pisano, B. Plaum, G. Plunk, P. Pölöskei, M. Porkolab, J. Proll, M.-E. Puiatti, A. Puig Sitjes, F. Purps, M. Rack, S. Récsei, A. Reiman, F. Reimold, D. Reiter, F. Remppel, S. Renard, R. Riedl, J. Riemann, K. Risse, V. Rohde, H. Röhlinger, M. Romé, D. Rondeshagen, P. Rong, B. Roth, L. Rudischhauser, K. Rummel, T. Rummel, A. Runov, N. Rust, L. Ryc, S. Ryosuke, R. Sakamoto, M. Salewski, A. Samartsev, E. Sanchez, F. Sano, S. Satake, J. Schacht, G. Satheeswaran, F. Schauer, T. Scherer, J. Schilling, A. Schlaich, G. Schlisio, F. Schluck, K.-H. Schlüter, J. Schmitt, H. Schmitz, O. Schmitz, S. Schmuck, M. Schneider, W. Schneider, P. Scholz, R. Schrittwieser, M. Schröder, T. Schröder, R. Schroeder, H. Schumacher, B. Schweer, E. Scott, S. Sereda, B. Shanahan, M. Sibilia, P. Sinha, S. Sipliä, C. Slaby, M. Sleczka, H. Smith, W. Spiess, D.A. Spong, A. Spring, R. Stadler, M. Stejner, L. Stephey, U. Stridde, C. Suzuki, J. Svensson, V. Szabó, T. Szabolics, T. Szepesi, Z. SzökefalviNagy, A. Tancetti, J. Terry, J. Thomas, M. Thumm, J.M. Travere, P. Traverso, J. Tretter, H. Trimino Mora, H. Tsuchiya, T. Tsujimura, S. Tulipán, B. Unterberg, I. Vakulchyk, S. Valet, L. Vano, B. van Milligen, A.J. van Vuuren, L. Vela, J.-L. Velasco, M. Vergote, M. Vervier, N. Vianello, H. Viebke, R. Vilbrandt, A. Vorköper, S. Wadle, F. Wagner, E. Wang, N. Wang, Z. Wang, F. Warmer, T. Wauters, L. Wegener, J. Weggen, Y. Wei, G. Weir, J. Wendorf, 
U. Wenzel, A. Werner, A. White, B. Wiegel, F. Wilde, T. Windisch, M. Winkler, A. Winter, V. Winters, S. Wolf, R.C. Wolf, A. Wright, G. Wurden, P. Xanthopoulos, H. Yamada, I. Yamada, R. Yasuhara, M. Yokoyama, M. Zanini, M. Zarnstorff, A. Zeitler, D. Zhang, H. Zhang, J. Zhu, M. Zilker, A. Zocco, S. Zoletnik, and M. Zuin. Overview of first wendelstein 7-x highperformance operation. Nuclear Fusion, 59(11):112004, jun 2019.

[25] Yu Gao, Joachim Geiger, Marcin Jakubowski, Peter Drewelow, Michael Endler, Kian Rahbarnia, Sergey A Bozhenkov, Matthias Otte, Yasuhiro Suzuki, Yühe Feng, Holger Niemann, Fabio Pisano, Adnan Ali, Aleix Puig Sitjes, Marco Zanini, Heinrich Peter Laqua, Torsten Stange, Stefan Marsen, Tamas Szepesi, Daihong Zhang, Carsten Killer, Kenneth Hammond, Samuel A Lazerson, Barbara Cannas, H Thomsen, Tamara Andreeva, Ulrich Neuner, Jonathan Schilling, Alexander Knieps, Michael Rack, and Yunfeng Liang. Effects of toroidal plasma current on divertor power depositions on wendelstein 7-x. Nuclear Fusion, 2019.

[26] Norbert Rust, Bernd Heinemann, Boris Mendelevitch, Alan Peacock, and Michael Smirnow. W7$\mathrm{X}$ neutral-beam-injection: Selection of the NBI source positions for experiment start-up. Fusion Engineering and Design, 86(6-8):728-731, October 2011.

[27] Samuel Aaron Lazerson, Pavlos Xanthopoulos, Harry Mynick, and David Gates. Ion temperature gradient turbulence modification in quasi-axisymmetry. Physics of Plasmas, 26(2):022509-8, February 2019. 